\title{
Existence and uniqueness of two fuzzy solutions to cooperative games
}

\author{
Erick González ${ }^{1}$ Rafael A. Espín ${ }^{1}$ Gustavo Mazcorro ${ }^{2}$ Rafael Espín $^{3}$ \\ ${ }^{1}$ Higher Technical Institute "José Antonio Echeverría”, Havana, Cuba \\ ${ }^{2}$ Instituto Politécnico Nacional-UPIICSA, Mexico City, Mexico \\ ${ }^{3}$ EXPLOMAT, Havana, Cuba \\ erickgc@cemat.cujae.edu.cu, espin@ind.cujae.edu.cu,gmazcorro@ipn.mx, rafael@explomat.geicon.gov.cu
}

\begin{abstract}
Fuzzy Negotiation Solution by Knowledge Engineering (FNSKE) and Compensatory Negotiation Solution by Knowledge Engineering (CNSKE) are two new solution concepts to n-person cooperative games. They involve a quantitative index, called Good Deal Index (GDI), which is the matrix solution of a recurrent equation. The existence and uniqueness of the GDI entail the existence and uniqueness of the solutions. Because of the strength of the hypotheses needed to proof uniqueness, and the convergence of the algorithm, those demonstrations are made statistically, using the Strong Law of Large Numbers. The proof of existence is made using the Schauder Theorem of fixed point.
\end{abstract}

Keywords: Fuzzy solution to an n-person cooperative game, Fixed point, Knowledge Engineering

\section{Introduction}

The Fuzzy Negotiation Solution by Knowledge Engineering, see [4,3], and the Compensatory Negotiation Solution by Knowledge Engineering, see [7], designate two kindred solution concepts to n-person cooperative games. In these models the axiomatic notion of rational choice [6] is replaced with a heuristic, composed by a set of negotiation principles, expressed in natural language. According to Knowledge Engineering, and the Nonaka and Takeuchi's classification, this is explicit knowledge [6].

For representing the negotiation principles in mathematical form, probabilistic fuzzy logic is used in FNSKE, and Compensatory Fuzzy Logic is used in CNSKE. The last of these involves conjunction and disjunction operators as logic functions satisfying axioms of Decision Theory.

FNSKE and CNSKE entail a set of quantitative bargaining indexes among $\mathrm{n}$ negotiators. One of them is the Good Deal Index (GDI), which is defined as the gains each player obtains in every possible coalition. The solution is an array in which the rows contain the GDI values for the players in the coalition and the truth value of the proposition: "likelihood to reach an agreement in the coalition framework".
Two other indexes are also proposed: the Counterpart Convenience Index 1 (CCI1) and the Counterpart Convenience Index 2 (CCI2). The CCI1 yields a ranking on the convenience of every player to negotiate in the set of all coalitions. The $\mathrm{CC} 2$ is an index that ranks the convenience of every player to negotiate in a particular coalition, given that all coalitions are formed, such that any coalition can negotiate with other coalitions as they were single players.

The GDI is the solution of a recurrent equation, hence fixed point theorems can be applied to prove the existence and the uniqueness of the solution, and the convergence of the algorithm. The aim of this paper is to demonstrate the existence of both solutions FNSKE and CNSKE through the Schauder Fixed Point Theorem [12]. The convergence of the fixed point algorithm to calculate the GDI, and the uniqueness of the GDI in the solutions, are examined statistically because of difficulties to apply fixed point theorems in such models.

\section{A fuzzy approach to cooperative n-person games}

A cooperative n-person game [9] is a pair $(\mathrm{N}, \mathrm{v})$, where $\mathrm{N}$ $=\{1,2, \cdots, \mathrm{n}\}, 1<\mathrm{n}<\infty$ is a set of players, and $\mathrm{v}$ is a mapping from $2^{\mathrm{N}}$ into $\Re$ satisfying properties (i) and (ii), below. A coalition is an element of $2^{\mathrm{N}}$

i. $\mathrm{v}(\varnothing)=0$

ii. $\quad \mathrm{v}(\mathrm{S} \cup \mathrm{T}) \geq \mathrm{v}(\mathrm{S})+\mathrm{v}(\mathrm{T})$, where $\mathrm{S}$ and $\mathrm{T}$ are disjoints coalitions of $2^{\mathrm{N}}$.

In this framework, [3] proposes a fuzzy solution concept based on expert knowledge from literature on negotiation. The structure is summarized in four propositions expressed in natural language. The propositions are $[1,5$, 8]:

1. A negotiation part has bargaining capacity if and only if the following conditions hold:

- The contribution of its institution to the settlement (agreement, or business) in discussion is important.

- The part can find feasible alternatives and some advantages if no settlement is reached, or its contribution is essential.

2. Any increase in contribution to the business by one of the parts, or an increase in benefits due to its corresponding alternatives, increases its bargaining capacity. 
3. The benefit obtained by each part is equal to the amount that it could obtain without the contribution of other parts, plus a portion of the additional benefit derived from the settlement. This increment obtained by each party is approximately proportional to its bargaining capacity.

4. A settlement is possible if and only if all the parts are important to the business and the corresponding benefit to every part is important to each of them.

This is an application of Knowledge Engineering, instead of the utilitarian rationality concept. "Knowledge Engineering is the discipline (of Artificial Intelligence) that allows building intelligent systems by means of the deduction of knowledge, having as central processes the acquisition, representation, manipulation and validation of this knowledge" [2].

Definition 2.1 The Good Deal Index (GDI) of negotiator $i$, from the point of view of negotiator $j$, in a given bargaining-set, is the benefit that $i$ could obtain if the collective benefits estimated by $\mathrm{j}$ prevailed, and the whole set of negotiators-including $\mathrm{j}$-had a similar performance in defense of their interests during the bargaining process.

In this model the institutions are represented by the players in $\mathrm{N}$, the bargaining-sets are represented by coalitions belonging to the power set $2^{\mathrm{N}}$, and the characteristic function represents the benefits obtained in the bargaining-sets. The expression of the GDI is (see [3]):

$\mathbf{X}(i, C)=\left\{\begin{array}{l}v(\{i\})+\frac{r(i, C)}{\sum_{j \in C} r(j, C)}\left[v(C)-\sum_{j \in C} v(\{j\})\right] \text { if } i \in C, \\ 0 \quad \text { if } i \notin C\end{array}\right.$

Where $r(i, C) \in[0,1]$ is the truth value of the fuzzy predicate "player $i$ has bargaining capacity in the bargaining set C ".

The fuzzy logic system used in this model is the Probabilistic Fuzzy Logic. The connectives in this system are:

- $\mathrm{u}(\mathrm{p} \wedge \mathrm{q})=\mathrm{u}(\mathrm{p}) \mathrm{u}(\mathrm{q})$. Conjunction.

- $u(p \vee q)=u(p)+u(q)-u(p) u(q)$. Disjunction.

- $u(\neg p)=1-u(p)$. Negation.

- $\mathrm{i}(\mathrm{x}, \mathrm{y})=\mathrm{d}(\mathrm{n}(\mathrm{x}), \mathrm{y})$. Natural Implication. Or, $\mathrm{i}(\mathrm{x}, \mathrm{y})=$ $\mathrm{d}(\mathrm{n}(\mathrm{x}), \mathrm{c}(\mathrm{x}, \mathrm{y}))$. Implication of Zadeh.

The following expression is a consequence of Proposition 2:

$$
r(i, C)=p(i, C) \wedge\left(a(i, C) \vee p^{2}(i, C)\right)
$$

Predicates $\mathrm{p}(\mathrm{i}, \mathrm{C})$ and $\mathrm{a}(\mathrm{i}, \mathrm{C})$ correspond to the statements "player $\mathrm{i}$ is important to coalition $\mathrm{C}$ " and "player $\mathrm{i}$ has feasible and advantageous alternatives to reach an agreement within $C^{\prime \prime} \cdot p^{2}(i, C)$ models the linguistic modifier related to "very" [11].

The following formula implies a strict fuzzy order:
$\mathrm{O}(\mathrm{C}, \mathrm{D})=\mathrm{o}(\mathrm{v}(\mathrm{C}), \mathrm{v}(\mathrm{D}))=$

$=\frac{0.5}{\lambda}\left[\frac{\mathrm{v}(\mathrm{C})-\mathrm{v}(\mathrm{D})}{\max _{\mathrm{E}, \mathrm{F} \in 2^{\mathrm{N}}}|\mathrm{v}(\mathrm{E})-\mathrm{v}(\mathrm{F})|}\right]+0.5, \lambda>1^{(3)}$

Where $=1$.

Thus, $\mathrm{p}(\mathrm{i}, \mathrm{C})=\mathrm{O}(\mathrm{C}, \mathrm{C} \backslash\{\mathrm{i}\})$ and $\mathrm{q}(\mathrm{i}, \mathrm{C})=\mathrm{o}(\mathbf{X}(\mathrm{i}, \mathrm{C}), \mathrm{v}(\{\mathrm{i}\}))$ correspond to the predicates "coalition $\mathrm{C}$ obtains more benefits than coalition $C \backslash\{\mathrm{i}\}$ " and "player i obtains more benefits in coalition $\mathrm{C}$ than in coalition $\{i\}$ ", respectively. These affirmations correspond, equivalently, to the statements "the contribution of $\mathrm{i}$ is important for coalition $\mathrm{C}$ " and "coalition $\mathrm{C}$ is important for player i", respectively. The predicate:

$\mathrm{S}(\mathrm{i}, \mathrm{C}, \mathrm{D})=\frac{0.5}{\lambda}\left[\frac{\mathbf{X}(\mathrm{i}, \mathrm{C})-\mathbf{X}(\mathrm{i}, \mathrm{D})}{\max _{\mathrm{E}, \mathrm{F} \in 2^{\mathrm{N}}}|\mathrm{v}(\mathrm{E})-\mathrm{v}(\mathrm{F})|}\right]+0.5$

corresponds to the statement " $\mathrm{i}$ obtains more benefits in coalition $\mathrm{C}$ than in coalition $\mathrm{D} "$.

The formula of the predicate corresponding to Proposition 4: "it is possible to reach an agreement within coalition $\mathrm{C}^{\prime \prime}$, is the following:

$$
f(C)=\left(\wedge_{j \in C}(p(j, C) \wedge q(j, C))\right.
$$

The affirmation: "there are advantageous and possible alternatives for player $\mathrm{i}$ to reach an agreement within coalition $\mathrm{C}^{\prime \prime}$ is mod(eled by:

$a(i, C)=v_{B \neq C},\{i\}<B(s(i, B, C) \wedge f(B))$

The value $\lambda=1.0494$ has been calculated experimentally. The GDI is to be calculated by the recurrent formula:

$\mathbf{X}(\mathrm{i}, \mathrm{C})=\mathrm{g}(\mathbf{X}(\mathrm{i}, \mathrm{C}))(6)$

Where, $g$ is the operator that transforms $\mathrm{n} \times \mathrm{m}$ Matrices into $\mathrm{n} \times \mathrm{m}$ matrices. It yields the GDI of all players in every coalition of the game. The solution of the game is given by:

$$
\begin{aligned}
& S=\left\{\left(\mathbf{X}\left(1, C_{j}\right), \mathbf{X}\left(2, C_{j}\right), \cdots, \mathbf{X}\left(n, C_{j}\right) ; f\left(C_{j}\right)\right):\right. \\
& \left.: j=1,2, \cdots, \operatorname{card}\left(2^{N}\right)\right\}
\end{aligned}
$$

Expression ( 7) is a set of vectors, each has $n$ entries as the division of worth among the players in the coalition, and an element that is the truth value of the function $\mathrm{f}(\mathrm{C})$ according to (5).

The Counterpart Convenience Index 1(CCI1) of the player $i$, in coalition $C$ and game $v$, is denoted by $D_{v}(i, C)$ and is equal to:

$$
D_{v}(i, C)=q_{v}(i, C) \wedge f_{v}(C)
$$


This index ranks coalitions by order of convenience for each player $\mathrm{i}$.

Definition 2.2 (see [3]) Let $\mathrm{v}$ be an n-person game and $\beta$ a partition of $\mathrm{N}$. A sub-game $\mathrm{v}_{\beta}$ of $\mathrm{v}$ and $\mathrm{B}$ is a game whose players are all the sets in $\beta$ (coalitions). A subgame satisfies: $\mathrm{V}_{\mathrm{p}}\left(\left\{\mathrm{F}_{1}, \mathrm{~F}_{2}, \ldots, \mathrm{F}_{\mathrm{n}}\right\}\right)=\mathrm{v}\left(\mathrm{U}_{\mathrm{i}=1}{ }^{\mathrm{n}} \mathrm{F}_{\mathrm{i}}\right)$. The Counterpart Convenience Index 2 (CCI2) is defined by:

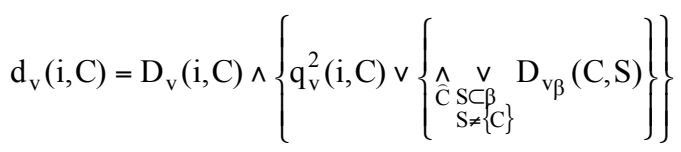

This index models the statement: "The bargaining set $\mathrm{C}$ is convenient for player $\mathrm{i}$ if the following conditions are satisfied:

- it is possible to obtain an advantageous agreement in this set.

- if the agreement is not very advantageous for $i$ then, no matter what structure of coalition had been presented, a convenience bargaining set $\mathrm{S}$ for the coalition $\mathrm{C}$ (as a player of $\mathrm{V}_{\beta}$ ) exists"

Let $\mathrm{v}$ be a sub-game, created after the negotiation, with a coalition structure $\beta$. The CCI2 indicates the convenience of renegotiating, where every $C \in \beta$ negotiates as a single player. The joint of the solution set from (7), the CCI1given by (8) and the CCI2 from (9), is called Fuzzy Negotiation Solution by Knowledge Engineering (FNSKE)

Remark 2.3 The formula (3) of O(C,D) is evidently illdefined for any game $(\mathrm{N}, \mathrm{v})$ in which $\mathrm{v} \equiv 0$. Such games will not be considered in this paper.

\section{Compensatory Negotiation Solution by Knowledge Engineering}

The Compensatory Negotiation Solution by Knowledge Engineering, see [7], is a fuzzy solution to n-person cooperative games in which the probabilistic fuzzy logic is replaced with Compensatory Fuzzy Logic. The Compensatory Fuzzy Logic is a logic system in which the conjunction and disjunction operators are idempotents and satisfy axioms of Decision Theory.

Conjunction, disjunction and negation operators in compensatory fuzzy logic are, respectively [3]:

- $\quad \mathrm{c}:[0,1]^{\mathrm{n}} \rightarrow[0,1]$, such that

$\mathrm{c}\left(\mathrm{x}_{1}, \mathrm{x}_{2}, \cdots, \mathrm{x}_{\mathrm{n}}\right)=\sqrt[n]{\prod_{\mathrm{i}=1}^{\mathrm{n}} \mathrm{x}_{\mathrm{i}}}$. Conjunction.

- $\quad \mathrm{d}:[0,1]^{\mathrm{n}} \rightarrow[0,1]$, such

that $\mathrm{d}\left(\mathrm{x}_{1}, \mathrm{x}_{2}, \cdots, \mathrm{x}_{\mathrm{n}}\right)=1-\sqrt[\mathrm{n}]{\prod_{\mathrm{i}=1}^{\mathrm{n}}\left(1-\mathrm{x}_{\mathrm{i}}\right)}$. Disjunction.

- $\mathrm{n}:[0,1] \rightarrow[0,1]$, such that $\mathrm{n}(\mathrm{x})=1-\mathrm{x}$. Negation.
- $\mathrm{i}:[0,1]^{2} \rightarrow[0,1]$, such that $\mathrm{i}(\mathrm{x}, \mathrm{y})=\mathrm{d}(\mathrm{n}(\mathrm{x}), \mathrm{y})$. Natural Implication. Or, $\mathrm{i}(\mathrm{x}, \mathrm{y})=\mathrm{d}(\mathrm{n}(\mathrm{x}), \mathrm{c}(\mathrm{x}, \mathrm{y}))$. Implication of Zadeh.

Compensatory Model 2 is obtained by substituting probabilistic operators with compensatory operators, and the fourth proposition above, about bargaining capacity, is replaced with the proposition:

4. A settlement is possible if and only if the following conditions are satisfied:

- All the parts are important to the business and the corresponding benefit to every part is important to each of them.

- The number of parts associated to the settlement is not large.

The change to the fourth proposition implies a change in (5). The new expression for the "likelihood to reach an agreement in the coalition $\mathrm{C}$ " is the following:

$f(C)=\left(\wedge_{j \in C}(p(j, C) \wedge q(j, C))\right) \wedge J(\operatorname{card}(C))$

Where $J(\operatorname{card}(C))$ is the membership function of the proposition: "the quantity of players in the coalition $\mathrm{C}$ is not large". Function $\mathrm{J}$ depends on the cardinal number $\operatorname{card}(\mathrm{C})$.

The function $\mathrm{J}$ is the negation of the sigmoidal membership function according to:

$$
\begin{aligned}
& \mathrm{J}(\operatorname{card}(\mathrm{B}))=1-\frac{1}{1+\mathrm{e}^{-\alpha(\operatorname{card}(\mathrm{B})-\gamma)},} \\
& \alpha=\frac{\ln (0.9)-\ln (0.1)}{\gamma-\beta} \quad, \gamma, \beta \in \mathbf{N} .
\end{aligned}
$$

Evidently $\mathrm{J}(\beta)=0.9$ and $\mathrm{J}(\gamma)=0.5$.

The function $\operatorname{sig}(\mathrm{x})=\frac{1}{1+\mathrm{e}^{-\alpha(\mathrm{x}-\gamma)}} \quad$ models $\quad$ the proposition "the quantity of players in the coalition $\mathrm{C}$ is large". The other formulas remain as stated.

The GDI in the Compensatory Model 2 is:

$$
\mathbf{X}(i, C)=\left\{\begin{array}{l}
v(\{i\})+\frac{r^{2}(i, C)}{\sum_{j \in C} r^{2}(j, C)}\left[v(C)-\sum_{j \in C} v(\{j\})\right] \text { if } i \in C,(11) \\
0 \quad \text { if } i \notin C
\end{array}\right.
$$

This means that players in every coalition have much bargaining capacity, according to the linguistic modifiers, or hedges, used empirically in fuzzy logic.

The Compensatory Negotiation Solution by Knowledge Engineering is the Compensatory Model 2, for $\beta=1$ and $\gamma=4$, the solution set defined by formula 7 , the CCI1 and the CCI2 with formulas 8 and 9 respectively.

These parameters have been estimated statistically, according to the best pair of values, such that the GDI in compensatory solution is the closest to the GDI in a probabilistic solution. The maximum relative error between the GDI of the two solutions is less than $5 \%$ for a probability of 0.95 . 
The advantage of CNSKE over FNSKE is that the idempotency of conjunction and disjunction operators gives to every membership function, obtained from the predicates, the possibility to be self interpreted. From the point of view of the measurement theory [6], these are cardinal decision functions.

\section{Preliminary topological results}

Theorem 4.1 (Schauder Theorem) [12]: Let $\mathrm{E}$ be a Banach space and consider a compact convex set $\mathrm{K} \subset \mathrm{E}$ with more than one point. Every continuous function $\mathrm{f}$ : $\mathrm{K} \rightarrow \mathrm{K}$ has at least one fixed point.

Theorem 4.2 [13]: Let $X$ be a compact space and $f$ a continuous mapping of $\mathrm{X}$ onto a topological space $\mathrm{Y}$. Then $Y=f(X)$ is itself compact.

Theorem 4.3 [13]: Every closed subset F of a compact topological space $\mathrm{T}$ is itself compact.

Theorem 4.4 (Tychonoff) [14]: The product of compact spaces is compact.

Theorems (4.2), (4.3) and (4.4) can be applied, in general, to compact sets, not exclusively to compact topological spaces, see [15].

\section{Proof of the existence of the FNSKE and CNSKE}

Theorem 5.1 The normed space $M_{m \times n}(\Re)$ of real matrices of order $m \times n$ is a Banach space.

proof

The infinity norm of $\mathbf{X} \in \mathrm{M}_{\mathrm{m} \times \mathrm{n}}(\Re)$ is defined by: $\|\mathbf{X}\|_{\mathrm{x}}=\max _{\mathrm{j}} \sum_{\mathrm{k}=1}{ }^{\mathrm{n}}\left|\mathbf{X}_{\mathrm{jk}}\right|[17]$.

Let $<\mathbf{X}^{1}, \mathbf{X}^{2}, \ldots>$ be a Cauchy sequence of elements of $\mathrm{M}_{\mathrm{m} \times \mathrm{n}}(\Re)$. For any $\varepsilon>0, \exists \mathrm{n}_{0} \in \mathbf{N}$, such that $\mathrm{r}, \mathrm{s}>\mathrm{n}_{0}, \| \mathbf{X}^{\mathrm{r}}$ $-\mathbf{X}^{\mathrm{s}} \|_{\infty}<\varepsilon$, or $\max _{\mathrm{j}} \sum_{\mathrm{k}=1}{ }^{\mathrm{n}}\left|\mathbf{X}_{\mathrm{jk}}^{\mathrm{r}}-\mathbf{X}_{\mathrm{jk}}^{\mathrm{s}}\right|<\varepsilon$. Hence, $\left|\mathbf{X}_{\mathrm{jk}}^{\mathrm{r}}-\mathbf{X}_{\mathrm{jk}}^{\mathrm{s}}\right|<$ $\varepsilon, \forall \mathrm{r}, \mathrm{s}>\mathrm{n}_{0}$ and $<\mathbf{X}^{1}{ }_{\mathrm{jk}}, \mathbf{X}_{\mathrm{jk}}^{2}, \ldots>$ is a Cauchy sequence of $\mathfrak{R}$.

Because $\Re$ is a complete space [14], $<\mathbf{X}^{1}{ }_{\mathrm{jk}}, \mathbf{X}^{2}{ }_{\mathrm{jk}}, \ldots>$ is a convergent sequence. This is a property that is satisfied for all pair of indexes, $\mathrm{j}$ and $\mathrm{k}$, where, $1 \leq \mathrm{j} \leq \mathrm{m}$ and $1 \leq \mathrm{k}$ $\leq \mathrm{n}$. Hence, $<\mathbf{X}^{1}, \mathbf{X}^{2}, \ldots>$ is convergent and $\mathrm{M}_{\mathrm{m} \times \mathrm{n}}(\Re)$ is a complete space. This proof is valid when using other norms.

Definition 5.2 Let $(\mathrm{N}, \mathrm{v})$ be an n-person cooperative game, $\mathbf{X} \in \mathrm{M}_{\mathrm{n} \times(2-1)}{ }^{\mathrm{n}}(\mathfrak{R})$ belongs to the set $\mathrm{K}(\mathrm{v})$, if:

$\mathbf{X}(\mathrm{i}, \mathrm{k})=\left\{\begin{array}{l}\mathrm{v}(\{\mathrm{i}\})+\eta\left(\mathrm{i}, \mathrm{C}_{\mathrm{k}}\right) \cdot \\ \cdot\left[\begin{array}{r}\mathrm{v}\left(\mathrm{C}_{\mathrm{k}}\right)-\sum_{j \in \mathrm{C}_{\mathrm{k}}} \mathrm{v}(\{\mathrm{j}\}) \\ 0, \text { if } \mathrm{j} \notin \mathrm{C}_{\mathrm{k}}\end{array}\right], \text { if } \mathrm{j} \in \mathrm{C}_{\mathrm{k}}\end{array}\right.$

Where, $\mathrm{i} \in \mathrm{N}, \mathrm{C}_{\mathrm{k}} \in 2^{\mathrm{N}}, \eta\left(\mathrm{i}, \mathrm{C}_{\mathrm{k}}\right) \geq 0$, and $\sum_{\mathrm{i}=1}{ }^{\mathrm{n}} \eta\left(\mathrm{i}, \mathrm{C}_{\mathrm{k}}\right)=1$.

Let us call $\mathrm{R}\left(\mathrm{C}_{\mathrm{k}}\right)=\left[\mathrm{v}\left(\mathrm{C}_{\mathrm{k}}\right)-\sum_{\mathrm{j} \in \mathrm{Ck}} \mathrm{v}(\{\mathrm{i}\})\right]$.
Remark 5.3 Evidently, GDI indexes corresponding to FSNKE and CSNKE belong to the set $\mathrm{K}(\mathrm{v})$.

Theorem 5.4 Let $(\mathrm{N}, \mathrm{v})$ be an n-person cooperative game. Then, $\mathrm{K}(\mathrm{v})$ is a convex set.

\section{Proof}

Let $\mathbf{X}_{1}, \mathbf{X}_{2} \in \mathrm{K}(\mathrm{v})$ satisfy $\mathbf{X}_{1}=\left[\mathbf{X}_{1}(\mathrm{i}, \mathrm{k})\right]$ and $\mathbf{X}_{2}=\left[\mathbf{X}_{2}(\mathrm{i}, \mathrm{k})\right]$, according to one of the formulas (1) or (11). $\eta_{1}\left(i, C_{k}\right)$, $\eta_{2}\left(\mathrm{i}, \mathrm{C}_{\mathrm{k}}\right) \in[0,1]$ and $\lambda \in[0,1] ; \lambda \mathbf{X}_{1}+(1-\lambda) \mathbf{X}_{2}=$ $\left[\lambda \mathbf{X}_{1}(\mathrm{i}, \mathrm{k})+(1-\lambda) \mathbf{X}_{2}(\mathrm{i}, \mathrm{k})\right]=$

$=\lambda \mathbf{X}_{1}(\mathrm{i}, \mathrm{k})+(1-\lambda) \mathbf{X}_{2}(\mathrm{i}, \mathrm{k})=$

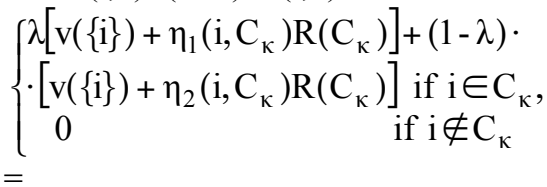

$\left\{\begin{array}{lc}\mathrm{v}(\{\mathrm{i}\})+\left[\lambda \eta_{1}\left(\mathrm{i}, \mathrm{C}_{\kappa}\right)+(1-\lambda) \eta_{2}\left(\mathrm{i}, \mathrm{C}_{\kappa}\right)\right] \\ \cdot \mathrm{R}\left(\mathrm{C}_{\mathrm{\kappa}}\right) & \text { if } \mathrm{i} \in \mathrm{C}_{\kappa}, \\ 0 & \text { if } \mathrm{i} \notin \mathrm{C}_{\kappa}\end{array}\right.$

$\eta_{1}\left(\mathrm{i}, \mathrm{C}_{\mathrm{k}}\right), \quad \eta_{2}\left(\mathrm{i}, \mathrm{C}_{\mathrm{k}}\right), \quad \lambda \in[0,1]$ implies that $\lambda \eta_{1}\left(\mathrm{i}, \mathrm{C}_{\mathrm{k}}\right)+(1-\lambda) \eta_{2}\left(\mathrm{i}, \mathrm{C}_{\mathrm{k}}\right) \geq 0$ and

$\sum_{\mathrm{i}=1}{ }^{\mathrm{n}}\left[\lambda \eta_{1}\left(\mathrm{i}, \mathrm{C}_{\mathrm{k}}\right)+(1-\lambda) \eta_{2}\left(\mathrm{i}, \mathrm{C}_{\mathrm{k}}\right)\right]$

$=\lambda \sum_{\mathrm{i}=1}{ }^{\mathrm{n}} \eta_{1}\left(\mathrm{i}, \mathrm{C}_{\mathrm{k}}\right)+(1-\lambda) \sum_{\mathrm{i}=1}{ }^{\mathrm{n}} \eta_{1}\left(\mathrm{i}, \mathrm{C}_{\mathrm{k}}\right)=\lambda 1+(1-\lambda) 1=1$. Hence, $\lambda \mathbf{X}_{1}+(1-\lambda) \mathbf{X}_{2} \in \mathrm{K}(\mathrm{v})$ and $\mathrm{K}(\mathrm{v})$ is convex.

Theorem 5.5 Let $(\mathrm{N}, \mathrm{v})$ be an n-person cooperative game. Then, $\mathrm{K}(\mathrm{v})$ is a compact set.

\section{proof}

$[0,1]$ is compact $[14]$, thus the topological space $[0,1]^{\mathrm{n}\left(2 \mathrm{n}_{-} 1\right)}$ is compact due to theorem (4.4).

Let $\mathrm{D} \subset[0,1]^{\mathrm{n}(2 \mathrm{n} 1)}$ be the set of vectors with elements $\eta_{\mathrm{i}}$, such that: $\sum_{\mathrm{i}=\mathrm{kn}+1}{ }^{(\mathrm{k}+1) \mathrm{n}} \eta_{\mathrm{i}}=1$ for $\mathrm{k}=0,1, \ldots, 2^{\mathrm{n}}-2$.

We prove now that $\mathrm{D}$ is closed.

Let $\left\{\mathbf{x}_{\mathrm{m}}\right\} \subset \mathrm{D}$ be a sequence convergent to $\mathbf{x}_{0}$. Suppose $\mathbf{x}_{0}$ $\notin \mathrm{D}$, then $\mathbf{x}_{0} \in[0,1]^{\mathrm{n}(2 \mathrm{n} 1)}$ because it is a closed set. The hypothesis implies that $\exists \mathrm{k}$, such that: $\sum_{\mathrm{i}=\mathrm{kn}+1}{ }^{(\mathrm{k}+1) \mathrm{n}} \mathbf{x}_{0 \mathrm{i}}=\mathrm{M}$ $\neq 1$; therefore, $\sum_{\mathrm{i}=\mathrm{kn}+1}{ }^{(\mathrm{k}+1) \mathrm{n}} \mathbf{x}_{\mathrm{mi}}-\sum_{\mathrm{i}=\mathrm{kn}+1}{ }^{(\mathrm{k}+1) \mathrm{n}} \mathbf{x}_{0 \mathrm{i}}=1-\mathrm{M}$.

If $\mathrm{M}<1$, then $1-\mathrm{M}=\sum_{\mathrm{i}=\mathrm{kn}+1}^{(\mathrm{k}+1) \mathrm{n}} \mathbf{x}_{\mathrm{mi}}-\sum_{\mathrm{i}=\mathrm{kn}+1}{ }^{(\mathrm{k}+1) \mathrm{n}} \mathbf{x}_{0 \mathrm{i}} \leq$ $\sum_{\mathrm{i}=\mathrm{kn}+1}{ }^{(\mathrm{k}+1) \mathrm{n}}\left|\mathbf{x}_{\mathrm{mi}}-\mathbf{x}_{0 \mathrm{i}}\right|$, let $\varepsilon=\frac{1-\mathrm{M}}{2 \mathrm{n}}$.

Because of the convergence of the sequence $\left\{\mathbf{x}_{\mathrm{m}}\right\}, \exists \mathrm{m}_{0}$ such that: $\left|\mathbf{x}_{\mathrm{m} 0 \mathrm{i}}-\mathbf{x}_{0 \mathrm{i}}\right|<\varepsilon \forall \mathrm{i}$ and $\sum_{\mathrm{i}=\mathrm{kn}+1}{ }^{(\mathrm{k}+1) \mathrm{n}}\left|\mathbf{x}_{\mathrm{m} 0 \mathrm{i}}-\mathbf{x}_{0 \mathrm{i}}\right|<$ $\frac{\mathrm{n}(1-\mathrm{M})}{2 \mathrm{n}}=\frac{1-\mathrm{M}}{2}, 1-\mathrm{M}<\frac{1-\mathrm{M}}{2}$, this is a contradiction, therefore $\mathbf{x}_{0} \in \mathrm{D}$.

If $\mathrm{M}>1$, then $\mathrm{M}-1=\sum_{\mathrm{i}=\mathrm{kn}+1}{ }^{(\mathrm{k}+1) \mathrm{n}} \mathrm{x}_{0 \mathrm{i}}-\sum_{\mathrm{i}=\mathrm{kn}+1}{ }^{(\mathrm{k}+1) \mathrm{n}} \mathbf{x}_{\mathrm{mi}} \leq$ $\sum_{\mathrm{i}=\mathrm{kn}+1}{ }^{(\mathrm{k}+1) \mathrm{n}}\left|\mathbf{x}_{\mathrm{mi}}-\mathbf{x}_{0 \mathrm{i}}\right|$, now, let $\varepsilon=\frac{\mathrm{M}-1}{2 \mathrm{n}}$. 
$\exists \mathrm{m}_{1}$ such that: $\left|\mathbf{x}_{\mathrm{mli}}-\mathbf{x}_{0 \mathrm{i}}\right|<\varepsilon \forall \mathrm{i}$ and $\sum_{\mathrm{i}=\mathrm{kn}+1}{ }^{(\mathrm{k}+1) \mathrm{n}}\left|\mathbf{x}_{\mathrm{m} 1 \mathrm{i}}-\mathbf{x}_{0 \mathrm{i}}\right|$ $<\frac{\mathrm{n}(\mathrm{M}-1)}{2 \mathrm{n}}=\frac{\mathrm{M}-1}{2}, \mathrm{M}-1<\frac{\mathrm{M}-1}{2}$, this is also a contradiction, hence $\mathbf{x}_{0} \in \mathrm{D}$.

$\mathrm{D}$ is a closed set because every convergent sequence of elements of $\mathrm{D}$ converges to an element of $\mathrm{D}$. It is a closed subset of a compact set, therefore, by theorem (4.3), D is compact.

$\tau: D \rightarrow \hat{D}$, where $\tau\left(\eta_{1}, \eta_{2}, \ldots, \eta_{n(2-1)}^{n}\right)=\mathbf{B}$ is a matrix and

$$
\begin{array}{ccc}
\mathbf{B}=\left(\begin{array}{ccc}
\mathrm{v}(\{1\})+\eta_{1} \mathrm{R}\left(\mathrm{C}_{1}\right) & \eta_{\mathrm{n}+1} \mathrm{R}\left(\mathrm{C}_{2}\right) & \cdots \\
\eta_{2} \mathrm{R}\left(\mathrm{C}_{1}\right) & \mathrm{v}(\{2\})+\eta_{\mathrm{n}+2} \mathrm{R}\left(\mathrm{C}_{2}\right) & \cdots \\
\vdots & \vdots & \vdots \\
\ldots & \eta_{\mathrm{n}\left(2^{\mathrm{n}}-1\right)-n+1} \mathrm{R}\left(\mathrm{C}_{2^{\mathrm{n}}-1}\right) \\
\cdots & \eta_{\mathrm{n}\left(2^{\mathrm{n}}-1\right)-n+2} \mathrm{R}\left(\mathrm{C}_{2^{\mathrm{n}}-1}\right) \\
\vdots & \eta_{2 \mathrm{n}} \mathrm{R}\left(\mathrm{C}_{2}\right) & \cdots \\
\cdots & \mathrm{v}(\{\mathrm{n}\})+\eta_{\mathrm{n}\left(2^{\mathrm{n}}-1\right)} \mathrm{R}\left(\mathrm{C}_{2^{\mathrm{n}}-1}\right)
\end{array}\right)
\end{array}
$$

Let us note that if $i \in C_{j}$, then the value $v(\{i\})$ is added to $\eta_{\mathrm{j}} \mathrm{R}\left(\mathrm{C}_{\mathrm{j}}\right)$ in $\mathbf{B}$.

$\hat{\mathrm{D}}=\tau(\mathrm{D})$.

This function is well defined. Suppose that $\tau\left(\eta_{1}, \eta_{2}, \ldots, \eta_{\mathrm{n}(2-1)}^{\mathrm{n}}\right)=\mathbf{B}, \tau\left(\eta_{1}, \eta_{2}, \ldots, \eta_{\mathrm{n}\left(2^{-1}\right)} \mathrm{n}\right)=\mathbf{B}^{\prime}$, and $\exists \mathrm{i}, \mathrm{j}$, where $\mathbf{B}_{\mathrm{ij}} \neq \mathbf{B}_{\mathrm{ij}}^{\prime}$, and $\mathrm{v}(\{\mathrm{i}\})+\eta_{1} \mathrm{R}\left(\mathrm{C}_{\mathrm{j}}\right) \neq \mathrm{v}(\{\mathrm{i}\})+\eta^{\prime}{ }_{1} \mathrm{R}\left(\mathrm{C}_{\mathrm{j}}\right)$ or $\eta_{1} R\left(C_{j}\right) \neq \eta^{\prime}{ }_{1} R\left(C_{j}\right)\left(R\left(C_{j}\right) \neq 0\right.$ because $\left.B_{i j} \neq B^{\prime}{ }_{i j}\right)$, hence $\eta_{1}$ $\neq \eta^{\prime}$, which is a contradiction because both matrices are the images of the same vector.

Let us prove that $\tau$ is a continuous mapping. Let $\left\{\boldsymbol{v}_{\mathrm{k}}\right\}_{\mathrm{k}=\mathbf{N}}$ a convergent sequence of elements of D to $\boldsymbol{v}_{0}$, let $\varepsilon>0$, $\exists \mathrm{m}_{0} \in \mathbf{N}$ such that: $\left\|\boldsymbol{v}_{\mathrm{k}}-\mathbf{v}_{0}\right\|_{*}<\frac{\varepsilon}{\mathrm{n} \hat{\mathrm{R}}}$, for every $\mathrm{k}>\mathrm{m}_{0}$, where $\hat{\mathrm{R}}=\max _{\mathrm{j}} \mathrm{R}\left(\mathrm{C}_{\mathrm{j}}\right)$. Using the definition of $\tau$, $\left\|\boldsymbol{\tau}\left(\boldsymbol{v}_{\mathrm{k}}\right)-\boldsymbol{\tau}\left(\boldsymbol{v}_{0}\right)\right\|_{w}=\max _{\mathrm{j}} \sum_{\mathrm{k}=1}{ }^{\mathrm{n}}\left|\left(\boldsymbol{v}_{\mathrm{j}}^{\mathrm{k}}-\boldsymbol{v}_{\mathrm{j}}{ }^{0}\right) \mathrm{R}\left(\mathrm{C}_{\mathrm{j}}\right)\right|<\varepsilon$, now with the maximum norm defined over the space of matrices, for every $\mathrm{k}>\mathrm{m}_{0}$. Hence, $\tau\left(\boldsymbol{v}_{\mathrm{k}}\right) \rightarrow \tau\left(\boldsymbol{v}_{0}\right)$, when $\mathrm{k} \rightarrow \infty$, and $\tau$ is a continuous mapping. According to the theorem (4.2), $\hat{\mathrm{D}}$ is a compact set.

$\mathrm{K}(\mathrm{v}) \subset \hat{\mathrm{D}}$, let $\left\{\mathbf{X}_{\mathrm{m}}\right\}_{\mathrm{m}=\mathbf{N}}$ be a convergent sequence of elements of $\mathrm{K}(\mathrm{v})$, suppose that $\left\{\mathbf{X}_{\mathrm{m}}\right\}_{\mathrm{m}=\mathbf{N}}$ converges to $\mathbf{X}_{0}$ $\in \hat{\mathrm{D}} \backslash \mathrm{K}(\mathrm{v})$, therefore, $\exists \mathrm{i}, \mathrm{j}$ (row index and column index of the matrices), such that $\mathbf{X}_{\mathrm{mij}}=0 \forall \mathrm{m} \in \mathbf{N}$ (because it is the difference between $\mathrm{K}(\mathrm{v})$ and $\hat{\mathrm{D}})$, but $\mathbf{X}_{0 \mathrm{ij}}=\mathrm{M}>0$. It follows from the hypothesis that $\left\|\mathbf{X}_{\mathrm{m}}-\mathbf{X}_{0}\right\|_{\infty} \geq \mathrm{M}>0$, and $\left\{\mathbf{X}_{\mathrm{m}}\right\}_{\mathrm{m} \in \mathbf{N}}$ is not a convergent sequence. This is a contradiction, hence, $\mathrm{K}(\mathrm{v})$ is a closed subset of the compact set $\hat{D}$, and $K(v)$ is compact according to the theorem (4.3).
Theorem 5.6 Let $(\mathrm{N}, \mathrm{v})$ be a cooperative n-person game. The operator $\mathrm{g}$ is continuous as function of $\mathbf{X}$, the GDI of the game.

proof

Let $\left\{\mathbf{X}_{\mathrm{m}}\right\}_{\mathrm{m}=\mathbf{N}} \subset \mathrm{K}(\mathrm{v})$ be a convergent sequence to $\mathbf{X}_{0}$. If $\mathrm{m} \rightarrow \infty$, then $\left\|\mathbf{X}_{\mathrm{m}}-\mathbf{X}_{0}\right\|_{\mathrm{x}} \rightarrow 0 . \quad \mathrm{r}\left(\mathrm{i}, \mathrm{C}_{\mathrm{k}}\right)$ is a continuous function of $\mathbf{X}$, because it is an algebraic combination of continuous functions that depend on $\mathbf{X}$, like the fuzzy operators and the fuzzy order function.

$\mathrm{r}\left(\mathrm{i}, \mathrm{C}_{\mathrm{k}}\right)>0$ because the fuzzy order function used in the models is divided by a value $\lambda=1.0494>1$, see (3), hence $\mathrm{p}$ and a are strictly positive operators.

Let us call $\overline{\mathrm{f}}\left(\mathbf{X}_{\mathrm{m}}\left(\mathrm{i}, \mathrm{C}_{\mathrm{k}}\right)\right)=\left[\left(1_{\mathrm{C}_{\mathrm{k}}}(\mathrm{i})\right) \frac{\mathrm{r}_{\mathrm{m}}^{\mathrm{s}}\left(\mathrm{i}, \mathrm{C}_{\mathrm{k}}\right)}{\sum_{\mathrm{j} \in \mathrm{C}_{\mathrm{m}}} \mathrm{r}_{\mathrm{m}}^{\mathrm{s}}\left(\mathrm{j}, \mathrm{C}_{\mathrm{k}}\right)}\right]$ and $\overline{\mathrm{f}}\left(\mathbf{X}_{0}\left(\mathrm{i}, \mathrm{C}_{\mathrm{k}}\right)\right)=\left[\left(1_{\mathrm{C}_{\mathrm{k}}}(\mathrm{i})\right) \frac{\mathrm{r}_{0}^{\mathrm{s}}\left(\mathrm{i}, \mathrm{C}_{\mathrm{k}}\right)}{\sum_{\mathrm{j} \in \mathrm{C}_{\mathrm{k}}} \mathrm{r}_{0}^{\mathrm{s}}\left(\mathrm{j}, \mathrm{C}_{\mathrm{k}}\right)}\right]$ matrices, where $\mathrm{s}=1$ in case of the FNSKE, $\mathrm{s}=2$ in case of the CNSKE and $1_{C_{k}}(i)=\left\{\begin{array}{l}1 \text { if } i \in C_{k} \\ 0 \text { if } i \notin C_{k}\end{array}\right.$

$\overline{\mathrm{f}}$ is a continuous function of $\mathbf{X}$, according to the results above, because all its elements are continuous functions of $\mathbf{X}$ and the ratio is always well-defined (with a non-null denominator).

$\left\|\mathrm{g}\left(\mathbf{X}_{\mathrm{m}}\right)-\mathrm{g}\left(\mathbf{X}_{0}\right)\right\|_{*} \leq$

$\max _{\mathrm{i}} \sum_{\mathrm{k}=1}{ }^{2 \mathrm{n}}-1\left\|\overline{\mathrm{f}}\left(\mathbf{X}_{\mathrm{m}}\right)-\overline{\mathrm{f}}\left(\mathbf{X}_{0}\right)\right\| \max _{\mathrm{i}} \sum_{\mathrm{k}=1}{ }^{2 \mathrm{n}-1}\left|\mathrm{R}\left(\mathrm{C}_{\mathrm{k}}\right)\right|$,

where $\mathrm{i}$ is the row index and $\mathrm{k}$ is the column index. Because of the continuity of $\overline{\mathrm{f}},\left\|\overline{\mathrm{f}}\left(\mathbf{X}_{\mathrm{m}}\right)-\overline{\mathrm{f}}\left(\mathbf{X}_{0}\right)\right\|_{\infty} \rightarrow 0$ for $\left\|\mathbf{X}_{\mathrm{m}}-\mathbf{X}_{0}\right\|_{\infty} \rightarrow 0$ and therefore, using last inequality above, $\left\|\mathrm{g}\left(\mathbf{X}_{\mathrm{m}}\right)-\mathrm{g}\left(\mathbf{X}_{0}\right)\right\|_{\mathrm{x}} \rightarrow 0$ for $\mathbf{X}_{\mathrm{m}} \rightarrow \mathbf{X}_{0}$. Hence, $\mathrm{g}$ is a continuous operator of $\mathbf{X} \in \mathrm{K}(\mathrm{v})$.

Theorem 5.7 If $(\mathrm{N}, \mathrm{v})$ is an n-person cooperative game. The operator $\mathrm{g}$, corresponding to the game, has at least one fixed point in $\mathrm{K}(\mathrm{v})$.

\section{proof}

$\mathrm{K}(\mathrm{v})$ is a convex compact set, according to theorems (5.4) and (5.5). It is a subset of a Banach space of matrices, according to the theorem (5.1) and $\mathrm{g}$ is a continuous operator by theorem (5.6), therefore, using the Schauder's Theorem (4.1), g has at least a fixed point in $\mathrm{K}(\mathrm{v})$, there exists the GDI and a solution of the game $(\mathrm{N}, \mathrm{v})$.

Due to the complexity necessary to make a theoretical proof of the uniqueness and the convergence of the algorithm of calculation, using fixed point theorems, this approach will be made statistically.

The uniqueness of the Fuzzy Negotiation Solution by Knowledge Engineering and the convergence of the algorithm were proved statistically in [4]. 
The GDI of the Compensatory Negotiation Solution by Knowledge Engineering was run 660 times for cases generated at random. The algorithm converged in all the runs. This result proves that the algorithm has a probability of convergence closed to 1 , according to the Strong Law of Large Numbers [16] of Bernoulli Trials. Also, this proves the existence of the GDI and, consequently, the existence of n-person game solutions for $\mathrm{n} \leq 9$.

To prove the uniqueness of the GDI and, hence, the uniqueness of the solution of the n-person games, the Strong Law of Large Numbers was used. 32 cases, 4 for each case of $n$-person game, where $2 \leq n \leq 9$, were randomly generated. The following algorithm was made:

1. One of the 32 cases of n-person games is chosen. The number of the case is denoted by $\mathrm{m}$, starting with $\mathrm{m}=$ 1.

2. The GDI of the current case is calculated 31 times.

3. If the norm of the difference between the first two calculated GDI is smaller than $10^{-6}$, then $\mathrm{S}_{1}=1$, else $\mathrm{S}_{1}=0$. If the norm of the difference between every pair of the first 3 GDI is smaller than $10^{6}$, then $S_{2}=1$, else $S_{2}=0$ and so on... If the norm of the difference between every pair of the 31 GDI calculated is smaller than $10^{-6}$, then $S_{30}$ $=1$, else $\mathrm{S}_{30}=0$.

4. If $\frac{\sum_{\mathrm{m}=1}^{30} \mathrm{~S}_{\mathrm{n}}}{30}=1$ then $\overline{\mathrm{S}}_{\mathrm{m}}=1$, else $\overline{\mathrm{S}}_{\mathrm{m}}=0$.

5. If $\mathrm{m}<32$, go to step 1 with $\mathrm{m}+1$, else go to the next step.

6. Compute $\hat{\mathrm{S}}=\frac{\sum_{\mathrm{n}=1}^{32} \overline{\mathrm{S}}_{\mathrm{m}}}{32}$.

Following the experiment described in the algorithm above, it was obtained a value $\hat{\mathrm{S}}=1$.

This means, according to the Strong Law of Large Numbers, that the probability of the uniqueness of the GDI is close to 1 for $n$-person games where $2 \leq n \leq 9$. These results arise from the Compensatory Negotiation Solution by Knowledge Engineering. Hence, the solution to an n-person game, where $2 \leq \mathrm{n} \leq 9$, of the Compensatory Negotiation Solution by Knowledge Engineering has a probability of uniqueness near 1.

\section{Concluding Remarks}

The Fuzzy Negotiation Solution by Knowledge Engineering and the Compensatory Negotiation Solution by Knowledge Engineering are novelty fuzzy solutions to n-person cooperative games. They involve a fuzzy solution based upon an index called Good Deal Index, which is calculated by the recurrent equation $\mathbf{X}=\mathrm{g}(\mathbf{X})$. Two fuzzy indexes are also included, the Counterpart Convenience Indexes 1 and 2.
Equation $\mathbf{X}=g(\mathbf{X})$, where $\mathbf{X}$ is a matrix, can be calculated numerically through a fixed point algorithm. Hence, the existence and the uniqueness of $\mathbf{X}$ and the convergence of the algorithm should be proved.

The existence of GDI, hence the fuzzy solution in both models, has been proved in this paper by applying the Schauder's Theorem. First, we showed that the GDI in both solutions belong to a compact and convex set. Then, we demonstrate that operator $\mathrm{g}$, which maps this compact convex set into itself, is continuous. These are the hypotheses of the Schauder Theorem on the existence of at least one fixed point in equation $\mathbf{X}=\mathrm{g}(\mathbf{X})$.

The theorems that prove the uniqueness of the fixed point and the convergence of the algorithm demand strong hypotheses, which are difficult to verify. Therefore, the proof of uniqueness of the solution and the convergence of the algorithm has been approached statistically by the Strong Law of Large Numbers. 32 cases of games were generated randomly, and the GDI of each of them was calculated 31 times. The GDI in every case was considered the same with a maximum relative error of $10^{-6}$.

Finally, the Strong Law of Large Numbers was used to prove the convergence of the calculation algorithm, generating 660 random cases. The algorithm converged for all of them.

\section{References}

[1] M. Bazerman and M. Neale, Negotiating Rationally. The Free Press, New York, 1992.

[2] B. Buchanan and E. Shortliffe, Knowledge Engineering, In: Rule-Based Expert Systems The MYCIN Experiments of the Stanford Heuristic Programming Project, Addison-Wesley, Massachusetts, 1984, 147-158.

[3] R. Espín, E. Fernández, G. Mazcorro and M. I. Lecich, A fuzzy approach to cooperative n-person games, European Journal of Operational Research 176:1735-1751, 2007.

[4] R. Espín, Quantitative indices for decision making. $\mathrm{PhD}$ thesis, Higher Technical Institute José Antonio Echeverría, Havana, Cuba, 2000 (in spanish).

[5] R.Fisher and W.Ury, Getting to Yes Negotiation Agreement Without Giving Penguin Books, New York, 1983.

[6] S. French, Decision Theory: An Introduction to the Mathematics of Rationality Halsted Press, NewYorkBrisbane-Toronto, 1986.

[7] E. González, R. Espín and G. Mazcorro, Fuzzy Negotiation Solutions of N-Person Cooperative Games by Knowledge Engineering in Bargaining, Group Decision and Negotiation, 21:133-152, 2012.

[8] H. Raiffa, The Art and Science of Negotiation Harvard University Press, London, 1982.

[9] L.C. Thomas, Games, Theory and Applications John Wiley, New York, 1984. 
[10] L.A. Zadeh, Fuzzy Sets Information and Control, 8:338-353, 1965.

[11] L.A. Zadeh, The Concept of a Linguistic Variable and its Application to Approximate Reasoning-II Information Sciences, 8:301-357, 1975.

[12] T.Zamifirescu, A generic view on the theorems of Brouwer and Schauder Mathematische Zeitschrift, 213:387-392, 1993.

[13] A.N. Kolmogorov and S.V. Fomin, Introductory Real Analysis Dover Publications Inc, New York, 1972.

[14] S.Lipschutz, Theory and problems of General Topology Editorial Ciencia y Técnica, Havana, 1965.

[15] G. Nagy, Real Analysis Kansas State Lecture Notes, Fall 2001, 2001.

[16] W. Feller, An Introduction to Probability Theory and Its Applications (Volume I) Editorial Revolucionaria, Havana, 1967.

[17] E. Isaacson and H.B. Keller, Analysis of Numerical Methods Editorial Pueblo y Educación, Havana, 1966. 